\title{
Augmented Reality Prototype to Introduce Gamelan Based on Web
}

\author{
Avriyasendy Ramadiyan ${ }^{1}$ and Sari Wijayanti ${ }^{1}$
}

\begin{abstract}
Gamelan is a set of musical instruments used to accompany an art show or ceremony that originated from Java, Bali and Lombok. Augmented Reality which was later shortened to AR is a technology that allows a computer to display the virtual objects appropriately in a real object in real time. Interest in the study the gamelan music instruments are still relatively low. Therefore, it takes an effort to introduce a more gamelan creative and innovative. With prototype samples demung, is expected to be an alternative to introducing gamelan to the public. Using the methods of action research and prototyping systems development methods in the design accuracy and speed of the model can be solved by good and with prototype samples demung, is expected to be an alternative to introducing gamelan to the public. Using a programming language javaScript prototype is expected this will be more flexible and accessible to anyone, anytime, anywhere.Conclusions based on the benefits and approval UAT respondents Augmented Reality gamelan, the rating given to a prototype is worth 3,067 and 3.4 which means that the respondents considered if the prototype can be used as a media to introduce gamelan.
\end{abstract}

Keywords-Gamelan, Augmented Reality,javaScript, Demung, Prototyping, Action Research.

\section{INTRODUCTION}

$\mathrm{G}$ amelan as part of a kind of percussion instrument is a type of tool that can be categorized at very old. Song dynasty, in the 10th century humans are more likely to play the musical instruments percussion type by hand or with the help of sticks. Some other examples of percussion instruments such as kolintang, drums, bedhug, talempong, and tambourine

As rich music gamelan has many kinds of ways to play, can be played with a slow tempo melodious and can also be played with a fast tempo and more loudly. When played with a slow tempo and melodious will cause a comfortable and relaxed feeling for the brain, otherwise if played with a fast tempo and loud will cause feelings of standby, ready and sharp. Both occur because the human brain while listening to music will respond with waves that occur in the brain (Fathoni, 2011).

Gamelan Music in Java is not only known as a regional music / 'Klenengan' (Javanese gamelan performances) but part and parcel of the culture and daily life - the Java community. In developed countries has been much research done on the tempo like (Salim, 2005), in a gamelan timbre there is a psychophysical dimensions, in particular is known to cause certain emotional responses. The psychophysical dimensions defined by (Thompson L.L, 1999) as "the voice of all the properties that can be felt freely through musical experience, knowledge and enculturation".

In the E-book titled "Balungan a Publication Of The American Gamelan Institute" (American Gamelan Institute, 1986), can be taken outline that is now no longer gamelan instruments - musical instruments for foreign countries - developed countries. They gradually learn how to play gamelan, even now has many gamelan number of experts from the state - other developing countries such as Australia, Japan, Denmark and the UK.

\footnotetext{
${ }^{1}$ Avriyasendy Ramadiyan and Sari Wijayanti is with Departement of Informatics, Faculty of Computer Sains, Universitas Dian Nuswantoro, Semarang, Indonesia. E-mail: sensdy_yadinamarii@yahoo.co.id; sari.wijayanti@dsn.dinus.ac.id.
}

\section{A. Augmented Reality}

Augmented Reality is a technology that allows a computer to display the virtual objects appropriately in a real object in real time. AR system was first introduced in Sutherland in 1965 , and until now continues to grow . According to (Hirokazu Kato, 2005), (Zhou Feng, 2008) Augmented Reality is a technology that involves depictions of computer graphics on the real world.

In 1999, (Hirokazu Kato, 2005), develop ARToolkit in HIT Lab and demonstrated at SIGGRAPH, in 2000, Bruce.H.Thomas, develop AR Quake, a Mobile Game $\mathrm{AR}$ is shown at the International Symposium on Wearable Komputers . In 2008, Wikitude AR Travel Guide, introducing Web G1 Phone tech AR, in 2009, introduced Saqoosha FlarToolkit which is an outgrowth of ARToolkit . FlarToolkit AR technology allows us to put on a website, because the result output FlarToolkit is Flash form. In the same year, Wikitude Drive AR-tech launched navigation system on the Web Platform. In 2010, across air using AR technology on the I-Phone 3GS. (Malin Vlada, 2009) .

Broadly speaking, the development of AR continues to occur but the AR itself by focusing is divided into three areas: (Persa, 2006)

1. Tracking technology.

2. Technology appearances.

3. Interaction technology.

Virtual objects display information can't be accepted by the user with their own senses. This makes the AR can be used as a tool to help perception and more interaction with the real world. The information displayed by the virtual objects helps users carry out activities in the real world. AR can be applied to all senses, including hearing, touch, and smell. Framework to formulate of possibility merging and melting the real world and the virtual world into a continuum of virtually.

$\mathrm{AR}$ is very dependent on the progress of $3 \mathrm{D}$ miniaturization and mobile computing (mobile computing). these data, the projection system technology effectively and quickly integrate a mini computer that is relatively less effective for really can make maximum AR interfaces, although getting closer to what we want with the continuous research conducted by experts. Various types of interfaces have been 
developed in the last 10 years, but no one has really worth it .

In the Application of Augmented Reality System must have a component to support the performance of digital image processing. According to ( $\mathrm{R}$ Silva, 2003) there is the component.

1. Scene Generator

2. Tracking System

3. Display

4. AR Devices

\section{B. Three.js}

Three.js is a JavaScript 3D engine developed by Ricardo Cabello Miguel or familiarly called MR.DOOB he is a programmer who lives in Barcelona, Spain. Mr.Doob along with several co-writing and reorder line WebGL thousands to form a new library called Three.js. Three.js famous lightest, with many examples of the use of, and using the scripting language JavaScript its use becomes easier. Here are the details of why the author uses Three.js:

1. Three.js hide the details of the 3D rendering

2. Three.js is an OOP (Object Oriented Programming)

3. Three.js is an open source library

4. Three.js more quickly and easily learned

5. Three.js support interaction

6. Three.js 3D can be used to build math

7. Three.js supports JSON file format

8. WebGL Three.js is an extensible language

9. Three.js support HTML5 Canvas 2D

The prototype is derived from software 3Ds Max and Sketchup. However that may be used in web via WebGL models that have been designed in the export using the utilities provided by the exporter three.js. There is also a net exporter for Blender or Maya.

\section{WebRTC}

WebRTC (Web Real Time connection) is an application that supports the HTML5 video tag. Historically, the RTC has been corporated and could say where the RTC itself requires complex technology of high audio and video to be licensed or developed to meet the technological development in the field of video conferencing. From WebRTC API required the needs of the chronology connection between $\mathrm{pc}$ to $\mathrm{pc}$ or to mobile. WebRTC API example is Media Stream (getUserMedia). WebRTC APIs are already available in the web browser such as Chrome, Firefox and Opera on the other WebRTC API can also be run on iOS and Sony.

\section{METHOD}

\section{A. Action Research}

The author uses the methods of action research in a way become a direct part of a group art show music musicians. It is expected that the use of action research methods authors know and recognize the type of gamelan and various things related to the gamelan.

Then taking into account suggestions from several artists gamelan authors decided to use demung as prototype samples, because demung is one type of gamelan music instruments are fairly fundamental at every gamelan art show.

\section{B. Systems Development Method}

Prototyping methods are used, because this method has a fast development cycle and testing work model ( prototype ) of new applications through a process of interaction and repetitive commonly used information systems specialists and business experts . Prototyping is also called rapid application design (rapid application design / RAD ) due to simplify and accelerate the system design .

Prototyping methods there are three (3) phases to be able to develop a software as shown below:

1) Collecting Supplies

Developers and users to meet and pick the general objectives, the needs are known and the picture of the parts of Augmented Reality that will be needed next. Thus the need for the developer obtained the information the developer is also required to create choice alternatives. If we look on the development of the system on the AR then one other alternatives suggested is to develop a mobile version of the AR gamelan. The advantages of mobile applications is a lot of touch screens so that the marker is used quite simply one with a lot of add events invisible so that each bilah will also trigger only one marker.

2) Designing

The design is done quickly and to represent all aspects of software design is known, and this design became the basis of building prototypes. At this stage developer did specification design and implement design. Design that has been successful presented to the user. Than design is performed on prototype and systems products.

3) Evaluation of Prototype

That gives developers a software prototype results that have been through the process requirements and design workshops. In testing developer asks user to give an opinion and evaluate. Then when user perceived grievances will get developer needs an overhaul from the start. Testing will expire if the user has given satisfaction with the software. Then the software will be given the changes desired by the user.

\section{Analysis and Design System}

1) Hardware and Software Requirements

To fulfill the hardware requirements of an application that will run a very large impact on the smooth use of the application itself. The computer specifications needed to meet the hardware requirements for this application to be installed into the system as follows:

a. Personal Computer

Personal computer is the minimum required to run this system is the middle-end computer with a processor with a speed of at least $2.2 \mathrm{GHz}, 256 \mathrm{MB}$ DDR2 $800 \mathrm{Mhz}$ RAM , 80GB Hard Disk Storage $\neg$.

b. Internet Connection

Internet connection can use the modem ( a tool for communication on the computer, for example, mobile phone USB modem ) whether internal or external, wi - fi signal, and others.

c. Webcam

Webcam is required to read the marker code which will be issued the 3D shape of a gamelan instrument.

d. System Operation

System operation is needed is a linux or fedora as the server system and windows xp, windows 7 and windows 
8. Also cannot be separated from the support $2.5 \mathrm{xx}$ version of the Chrome web browser that supports WebGL and WebRTC.

e. 3ds Max

As an aide in designing 3D objects modeling.

f. Web Browser ( Chrome )

As the media to run Augmented Reality and WebGL.

\section{System Design}

System to be built based on web. In the media application will be made a markers with predefined patterns where each pattern will issue a different sound and $3 \mathrm{D}$. As for who will emerge is demung partition from 1 to 7 .

1) Analysis System

The figure below is a diagram that illustrates use case model, obtained through the process of gathering information identified in several use case .

Model analysis of the system requirements will be the starting point of the design activity. Below is the use case of the system being designed .

\section{a. Use Case User}

Refer to figure 3, In these picture above described needs of the system, which is obtained through the process of gathering information to run augmented reality. With the initial condition is not detected and the marker has not been any executions following is a description of the Use Case diagram above.

Then refer to table 1, it will explain about description of use case user. That shown of action user with system augmented reality.

b. Activity Diagram

The design further to model is sequence of activities, and procedure logic is to devise an activity diagram where the activity diagram describe activities of the actors. Design of activity diagram is done to use case has been defined on designing use case diagrams, and in accordance with the scenario that has been designed previously. Refer to figure (7) from references activity diagram.

c. Actor Identification

Identify the person or device that will use the system is the initial stage of analysis. Person or device is called the actor, the actor presented the role of the person or device while the system operates. Actors in this application are as follows. Actor has been definition in table 2 .

\section{d. Sequence Diagram}

Refer to figure (8) explained that the user put the marker in front of the camera which is then detected by system. Furthermore, if the data is valid id marker will be given the status of age $=0$ which means that the system successfully match the id marker. After giving age status system will add the model to a condition detector would then load the model that added earlier to camera. Also described as a marker to the touch, then the condition will disappear then detector will delete the previously defined models. Set age will be created $>1$ Will call the audio sound that has been stored in the id of each marker. After a look back markers then the system will read the marker back then provide a set age $=0$. after a set age $=0$ then the system will add tween animation which displays each model and animation to camera as well as adding a model that had been lost because of the marker touched. e. Class diagram

Refer to figure (9) after built sequence diagram, class diagram need to classifying so that in the event of development and re-design after first testing will not require too much time.

f. Design Source

After making the design of the system to be built, then the next stage is the design source design results, in this case create source using a programming language. This system aims construction the extent to which the development takes place so that progress can be changed if there is input from the user.

The results of the design source for the design of system models is a website or web-based applications using HTML and Web programming language javaScript assisted by local sever web with XAMPP as a local URL (localhost).

\section{RESULT AND DISCUSSION}

After the design is completed the basic design of the model, sound, and animation will be formed. The next step is the evaluation of the prototype.

\section{A. Evaluation Prototype}

Evaluation is needed to determine how well developed quality of the prototype . Evaluation can be done using the blackbox and whitebox testing. User satisfaction evaluation is also used in this activity using UAT(User Acceptance Testing)

\section{1) Load Ancak And Bilah Gamelan}

Refer to figure (10) that's figure is complete when all of the markers placed simultaneously by a camera that is affordable. How to play this demung by closing the threshold marker so the marker will disappear.Than it will make a sound and animation run but users are asked to be careful because the tracer AR is continuously searching continuously, so if there is no proper marker placement AR will not be stable. Also serving as a benchmark of success is the intensity of light would affect.

\section{2) Sound And Animation}

Refer to table (11) there conducted a test by closing the threshold of a marker then the action that ensued is a discharge of animation and sound of each marker is missing. The test will do continuously too, from 1 to 7 and record the result

\section{B. User Acceptance Testing}

User Acceptance Testing is a test performed for testing out a product from the user's perspective. This method is used to determine the response, and the lack of response to this application. In this test, the authors tested demung Augmented Reality applications as many as 30 people there are Javanese gamelan artists , graduate students, senior high schools and junior high schools students. Testing will giving questionnaires index 1 will be multiplied 4,2 multiplied by 3 , index 3 multiplied by 2 and index 4 multiplied by 1 . In this questionnaire there are three kinds of sub-chapters there is :

\section{1) Augmented Reality and Demung}

Testing Augmented Reality and demung aims to determine level of user knowledge about AR and demung. Testing is also useful to introduce demung for 
respondents who don't know one of the Javanese gamelan musical instruments, also introduced a web based AR technology. This subsection ask about the knowledge and approval about augmented reality.

Refer to table (3) this test have 8 questions where 2 questions on number 6 and 7 are the core. Question number 6 is ask about knowledge the gamelan was exhibited in the technology of augmented reality and question number 7 ask about agreement respondent if gamelan developed in augmented reality technology. In number 6 have 1 - 4 answer from don't know to very know. And there is a detail about number 6.

From table 3 the explain is $0 \%$ respondent so knowing, $3.33 \%$ know , 36.67\% less know and $60 \%$ respondent said ever know about augmented reality gamelan. From this data we can visualize to pie chart as figure 4

From table number 3 we can get rate of question use rating math like:

Rating $=(($ eql index $1 * 4)+($ eql index $2 * 3)+($ eql index

$3 * 2)+($ eql index $4 * 1))$ / eql respondent

where eql index is equal total number input variables and eql respondent is equal of people who tested.

Next questions is number 7. Output data looks like table 6 . From table 5 explanation is $23.33 \%$ respondent very agree , $60 \%$ agree , $16.67 \%$ less agree and $0 \%$ don't agree if gamelan developed in augmented reality technology. From this data we can visualize to pie chart as figure 6.

2) Display and Audio

Display and audio testing aims to determine the level of success design process. To create object real and sound is good require some test and research library source code.

3) Marker, Camera and Light Intensity

Marker, Light And Camera Intensity testing will aims to determine the success of the user to compose the marker ,the influence of light and success in capturing the webcam camera object augmented. In this section user who have knowledge about augmented reality has not get difficulty to run AR gamelan. Marker placed, camera scope and light intensity would gave big trouble if respondent and people didn't understand how augmented reality work. Markers that are printed when having length and width are not the same then the markers tend to be difficult to detected . Moreover, if the height and width have the same but there are one or more markers which have wide different then the objects will be displayed differently, can be bigger or smaller.

Light condition also give determine success prototype to run . Intake questionnaires conducted in several places with varying light conditions so the results of the successful running prototype is also different . Camera also has a significant role in the success of the running prototype . Angle and height are used also varies.

\section{Conclusion}

Become from research and questionnaire augmented reality, the authors can draw conclusions as follows :

1) Development of gamelan using Augmented Reality technology with sample demung can be used as an interactive media to help introduce gamelan to young people and the general public.

2) UAT based on find out if the gamelan was exhibited in the technology of augmented reality and respondents agreement regarding the benefits, the rating given to a prototype is worth 1.43 and 3,067 which means the respondents considered if the prototype can be used as a media to Introduce gamelan.

From limitations response, too many use marker and to many use tools in this prototype, there's need to be a breakthrough prototype with using single marker. So tracing is don't too heavy. With the help smart phone tablet hope this prototype will more responsive, more easily and more flexible. Coupled with a network connection so players with other players. This suggest that an attempt to improve. This is the subject of our future work.

\section{REFERENCES}

[1]. American Gamelan Institute. (1986). Balungan. A Publication of The American Gamelan Institute , 10 - 42.

[2]. Fathoni, M. (2011). Augmented Reality. Augmented Reality alat perkusi , 2-3.

[3]. Fischer, J. (2006). Rendering Methods For Augmented Reality. Hasibuan, Z. A. (2007). Metodologi Penelitian . Pada Bidang Ilmu Komputer Dan Tekhnologi Informasu , 79.

[4]. Hirokazu Kato, M. B. (2005). A Registration Method Based On Texture Trackibg Using Artoolkit.

[5]. Malin Vlada, G. A. (2009). The Potential Of Collaborative Augmented Reality In Education.

[6]. Persa, S. F. (2006). Sensor Fusion In Head Pose Tracking For Augmented Reality. 5-7.

[7]. R Silva, J. O. (2003). Introduction To Augmented Reality .

[8]. Salim, D. (2005). Emosi Musikal Dalam Gamelan Jawa.

[9]. Supanggah, R. (2004). Gatra. A Basic Consept of Traditional Javanese Gending , 5 - 10

[10]. Thompson L.L, B. W. (1999). A Cross-Cultural Investigation of The Perception of Emosion In Music. Phsycofisical and Cultural cues , 43 - 64 .

[11]. Trip, D. (2005). Action Research. A Methodological Introduction .

[12]. Yuen, S. C.-Y. (2009). Augmented Reality. An Overview and Five Directions for Augmented Reality in Educatio .

[13]. Zhou Feng, D. B.-L. (2008). Trends In Augmented Reality Tracking, Interaction And Display. A Review Of Ten Years Of ISMAR .



Figure 1. Continuum of virtuality



Figure 2. Prototyping method process 


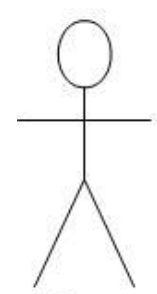

User

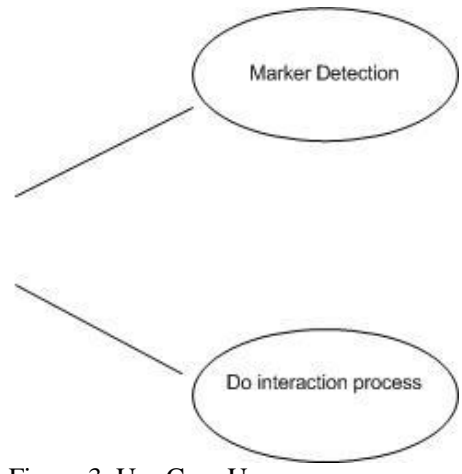

Figure 3. Use Case User apakah anda pernah mengetahui jika perangkat gamelan diperagakan dalam tekhnologi Augmented Reality

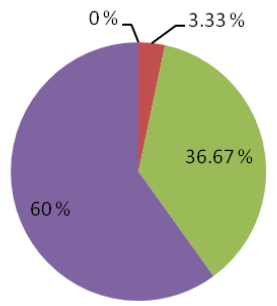

-1. sangat mengetahui

- 2. mengetahui

=3. kurang mengetahui

- 4. tidak mengetahui

Figure 4. Visualization from question number 6

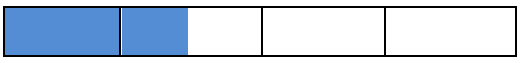

Then rate for number 6

Rating : $43 / 30=1.43$

Interval Rating:

$0-1$ : categorized not know

1-2: categorized less know

2-3: categorized know

3-4: categorized so knowing

Figure 5. Rating the response of respondents to knowledge gamelan instruments brought to the technology of Augmented Reality before

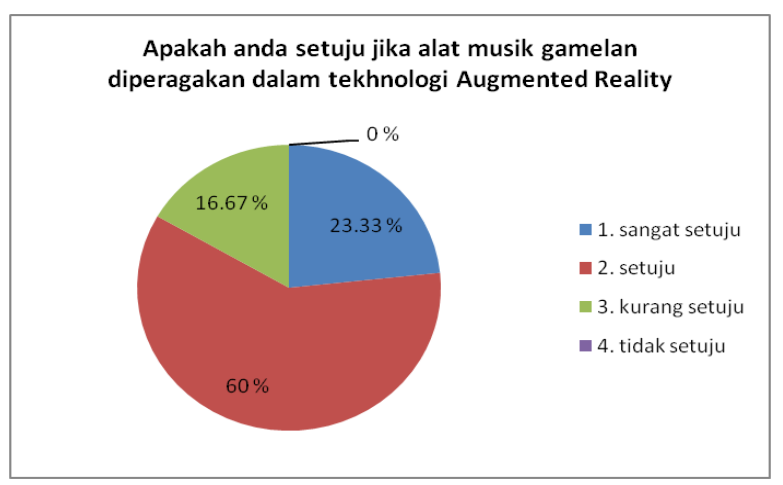

Figure 6. Visualization from question number 7

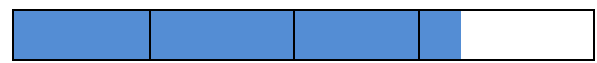

Interval rating :

0 -1: categorized not agree

1-2: categorized less agree

2-3: categorized agree

3-4: categorized very agree

Figure 7. Rating the response of respondents to the gamelan instruments brought to the technology of Augmented Reality

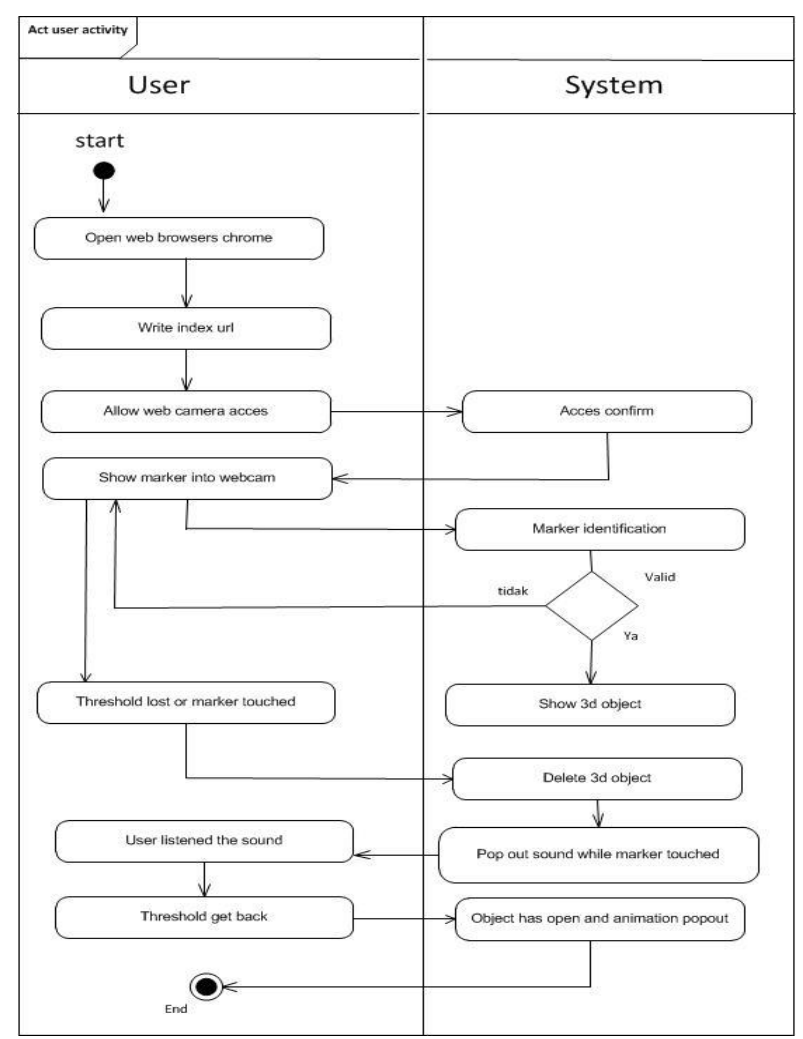

Figure 7. Activity Diagram User, The picture above is used to define measures of the work system to the user 


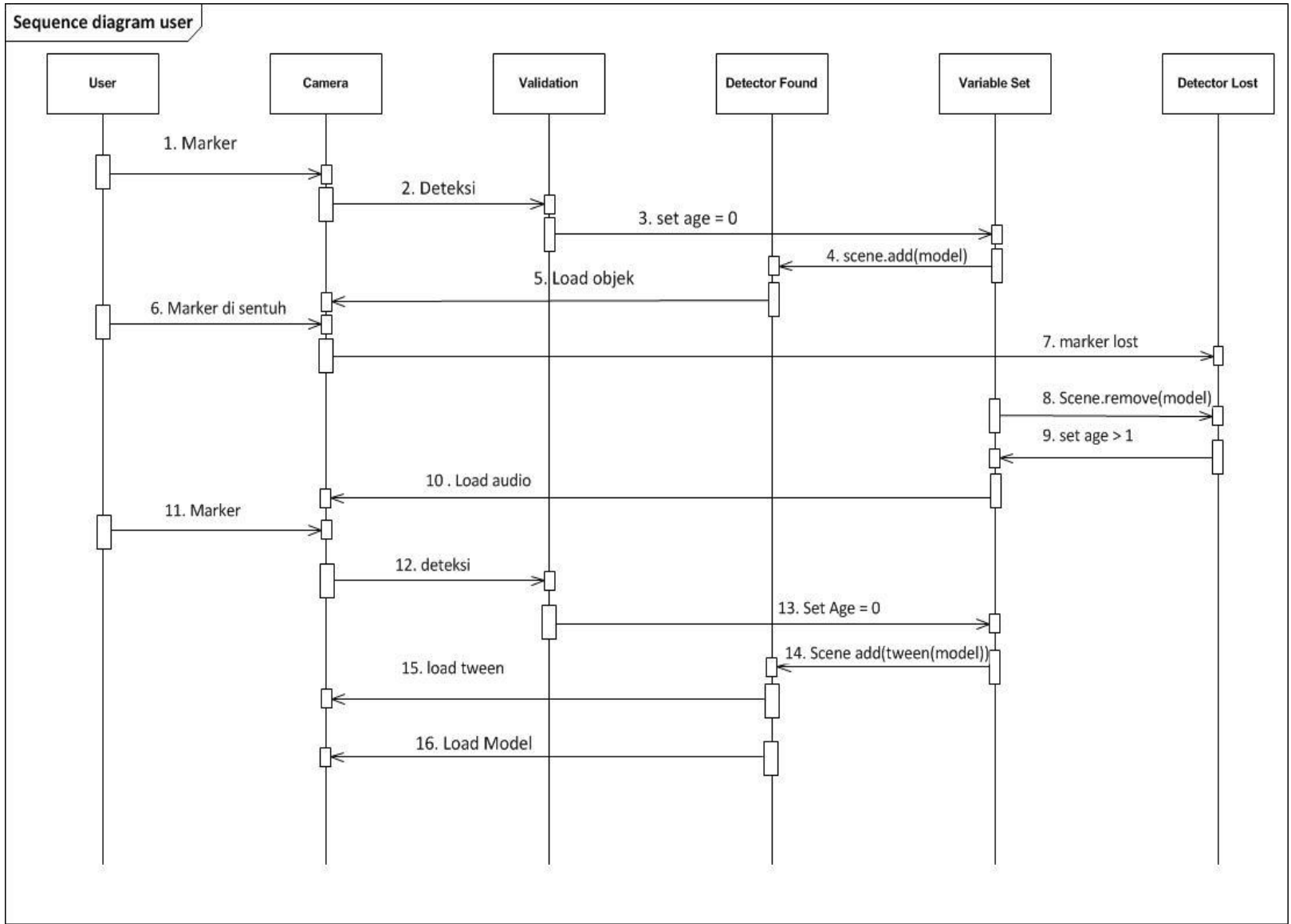

Figure 8 . Sequence diagram user, sequence diagram above is the activity that will be carried by user and system



Figure 9. Class Diagram, class diagram depicting the location of class in source code augmented reality 


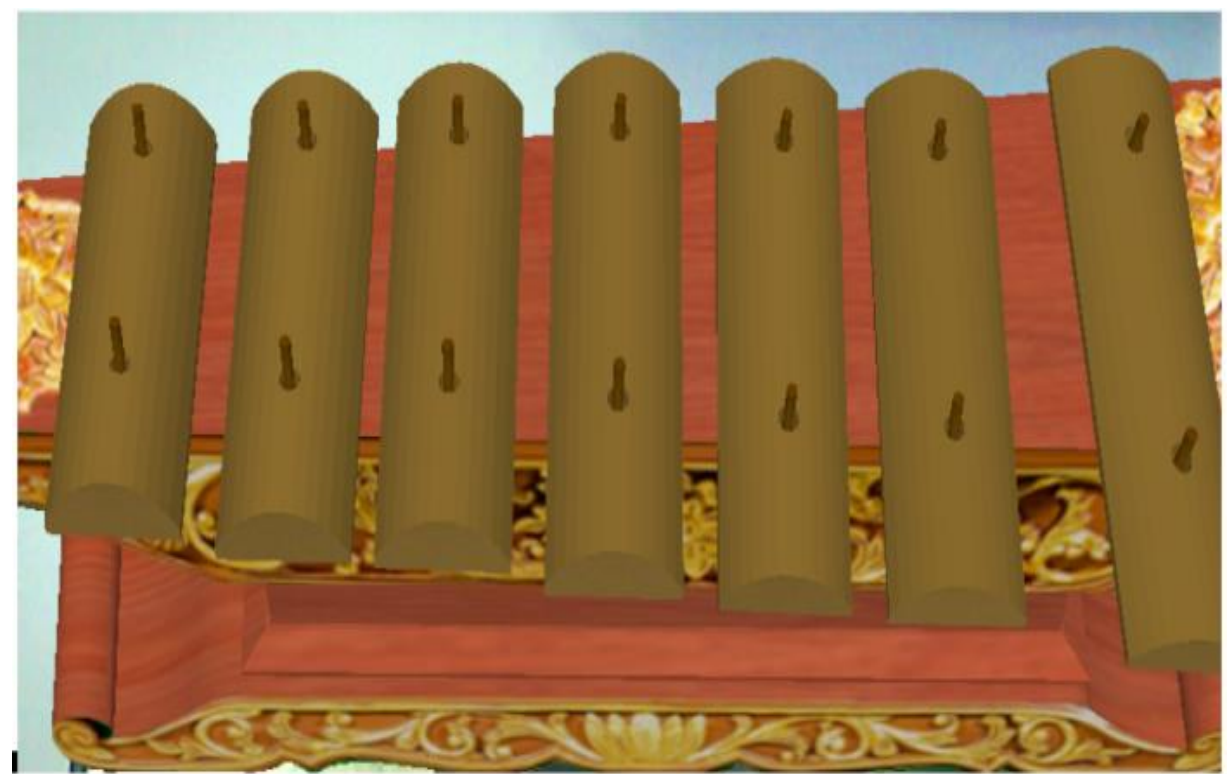

Figure 10. Load ancak and bilah gamelan, so the picture above is the result of several markers that have been placed in sequence position

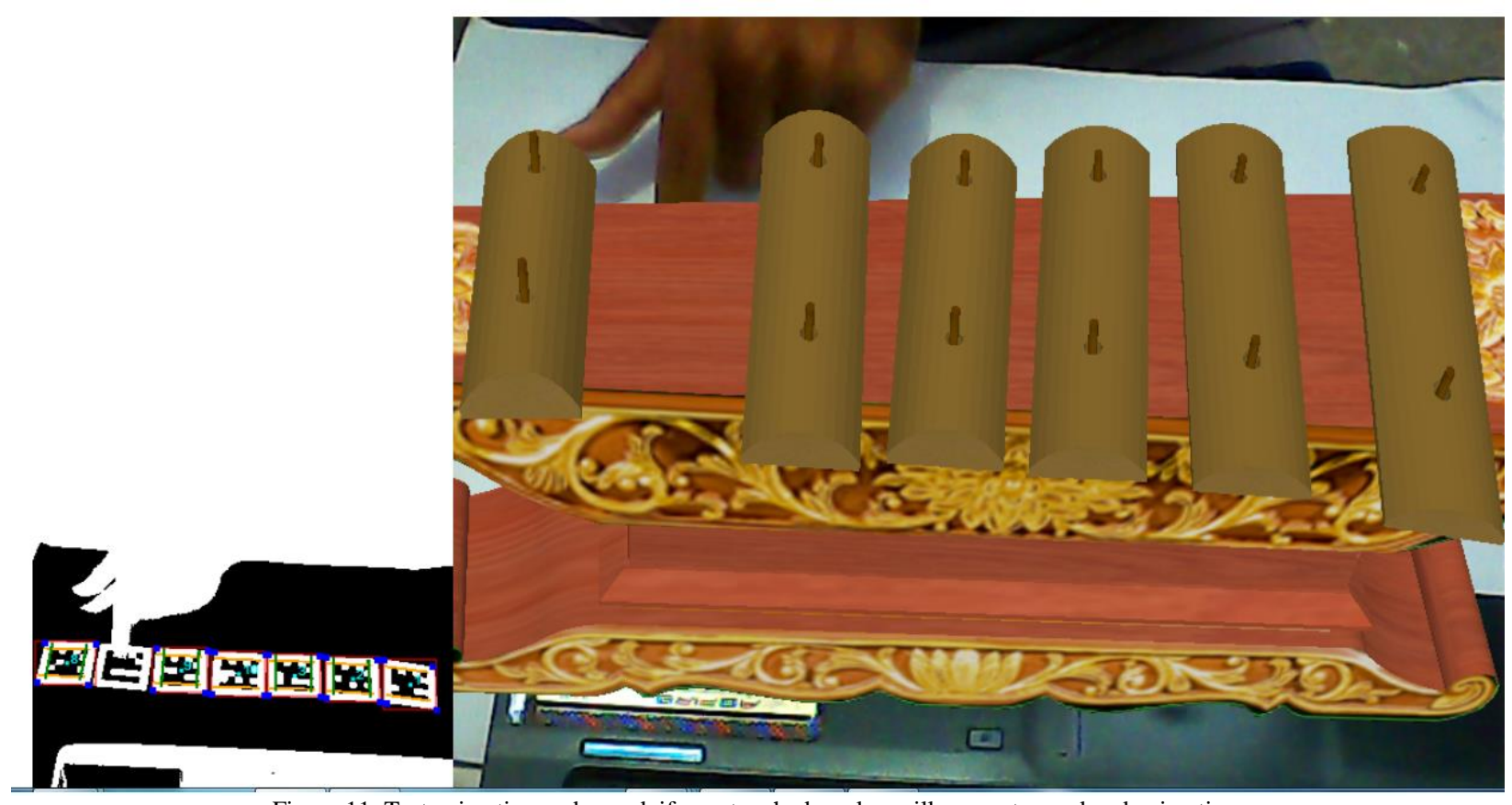

Figure 11. Test animation and sound ,if user touched marker will pop out sound and animation 